\title{
MODOS DE EDUCAÇÃO ${ }^{1}$
}

\author{
Joana A. Fernandes Silva ${ }^{2}$
}

Em primeiro lugar, a experiência social em todo o mundo é muito mais ampla e variada do que o que a tradição científica ou filosófica ocidental conhece e considera importante. Em segundo lugar, esta riqueza social está a ser desperdiçada.

Boaventura dos Santos

\section{RESUMO}

Neste texto, proponho-me a pensar nos modos de poder que envolvem as escolas frequentadas por alunos indígenas e a trazer um questionamento na fé que temos na ciência ocidental, ou o que o autor citado chama de epistemologias do norte. A escola será pensada a partir de uma perspectiva da dominação colonial e a partir das contribuições de alguns autores, entre outros, tais como Gersem Baniwa e Boaventura dos Santos, dois críticos da colonialidade do poder.

PALAVRAS-CHAVE: Escola indígena. Ciência. Epistemologia. Colonialidade e descolonização.

\section{ABSTRACT}

In this text, I propose to think about the modes of power that involve the schools frequented by indigenous students and to bring a questioning in the faith that we have in Western science, or what the author quoted calls Northern epistemologies. The school will be thought from a perspective of colonial domination and from the contributions of some authors, among

1 Percília e Silivan Panhi, do povo Apinajé, colaboraram com este texto.

2 Doutora em Antropologia Social pela Universidade de São Paulo. Professora titular aposentada da Faculdade de Ciências Sociais da Universidade Federal de Goiás (UFG). Professora efetiva da Pós-graduação em Antropologia Social (UFG); e professora no Curso de Educação Intercultural do Núcleo Takinahakỹ de Formação Superior Indígena (NTFSI), também, na UFG. Santo Antônio de Goiás, GO, Brasil. E-mail: joana.fernandes@gmail.com. 
others, such as Gersem Baniwa and Boaventura dos Santos, two critics of the coloniality of power.

KEYWORDS: Indigenous school. Science. Epistemology. Coloniality and decolonization.

Muitos argumentam, afirmou Boaventura em uma palestra na Universidade Federal de Minas Gerais, que o colonialismo já acabou! Mas ele continua a vigorar nos modos de poder, de saber, de interagir, no racismo, na xenofobia. Neste texto, proponho-me a pensar nesses modos de poder que envolvem as escolas frequentadas por alunos indígenas e a trazer um questionamento na fé que temos na ciência ocidental, ou o que o autor citado chama de epistemologias do norte.

Penso que o que se ensina, como se ensina e como se aprende tem um eixo orientador que está ligado com o tipo de sociedade que ensina, com o tipo de cosmologia e de visão de mundo e com o tipo de epistemologia dessa sociedade. O ato de ensinar é muito condicionado por essas variáveis.

$\mathrm{O}$ que se ensina a uma criança pequena? Um modo de ser? Conhecimentos? Técnicas? Filosofia? Cosmologia? Moral? Ciência? Essas perguntas permitem inferir que há tantas maneiras de educar, quantas sociedades existem.

Há processos muito distintos de ensinar e de aprender. Há muitos processos de aprendizagem de conteúdos que ocorrem de maneira diferente da instituição escolar, onde a cotação do aluno por notas são desnecessárias. Há também outras maneiras de aprender: "Menos atenção ao conteúdo", como disse Gersem Baniwa ${ }^{3}$ e "mais atenção ao processo de aprendizado e ao uso do aprendizado". Ele lembra que aprender em uma sociedade indígena é muito diferente do processo escolar. Nas tradições indígenas, muitas vezes o que importa são as formas de produção, de divulgação e de uso dos saberes, e não do conteúdo, segundo Gersem Baniwa.

Não há muitos estudos sobre a educação para membros de uma sociedade indígena. Ercivaldo Damsokekwa (2016) mostrou, em sua dissertação de mestrado, que entre os Xerente-Akwẽ há uma educação sistemática que se organiza e de acordo com a prontidão da

3 Conferência ministrada no III Congresso Internacional Formación en Educación Intercultural y Praticas de Descolonizacion en America Latina, 26 de julho de 2017. 
classe de idade. Cada etapa de idade corresponde a certo conteúdo de aprendizado, que é passado pelos familiares.

No caso dos Xerente, povo Macro-jê, cujas aldeias contavam com o warã, ou casa dos homens, uma parte de educação formal era oferecida para meninos e para meninas a partir de oito anos até o casamento, quando, então, alguém passa a ser considerado adulto. Neste local, segundo Damsokekwa, no Warã, são repassados conteúdos ligados à tecnologia, história, cosmologia e aí, verdadeiramente, os conteúdos epistemológicos são apreendidos pelos meninos, meninas e jovens.

No entanto, Damsokekwa (2016) observa que:

o saber de um ancião, por mais que seja especializado, é abrangente. Já a educação escolarizada organiza os conhecimentos em disciplinas, que são ensinadas de forma isolada. Essa contradição entre a forma Akwẽ e a forma ocidental de ensinar e de aprender resulta em conflitos entre as gerações mais velhas, que se orientam pela oralidade e os jovens que frequentam a escola.

Davi Kopenawa critica nossa maneira de escrever e de pensar. Segundo ele, nossos pensamentos são confusos, pois vivemos no meio do barulho de carros, aparelhos; somente temos confiança no processo de aprender se colocarmos nossas ideias nas peles de papel. Os Yanomamo, como sonham, aprendem pelos sonhos, adquirem a sabedoria sonhando. Ele afirma literalmente: "Eu não aprendi a pensar as coisas da floresta fixando os olhos em peles de papel. Vi-as de verdade, bebendo o sopro de vida de meus antigos com o pó de yãkoana que me deram" (2015).

O processo de transformação de um bebê, em um membro da sociedade, sabedor de sua cultura, de suas técnicas, de sua cosmologia, é mesmo um longo processo que, mesmo após o casamento, pode se estender pela vida adulta. Este é o caso da formação de cantores, de sábios que fazem discurso em uma língua Akwẽ-Xerente diferenciada da linguagem do cotidiano, de pajés, dos conhecedores de plantas medicinais e de cantores.

Há uma classe de papeis sociais, bem como campos específicos de conhecimento, tais como o de especialistas em plantas, entre os Xerente há diversos especialistas em plantas: em plantas da mata, plantas do campo, plantas do cerrado, entre outras. De modo que o 
significado de plantas é muito distinto do que é para não indígenas. As plantas têm vontade própria, tem espíritos, tem donos. Não se pega uma planta como nós o fazemos. É necessário obter permissão de seu senhor. Violar essa regra pode significar ficar doente. Essa concepção, entre outras, traduz toda uma cosmologia que os não indígenas sequer desconfiam. E, também, eles não falam muito sobre isso.

Kopenawa, ao se referir à floresta entre os Yanomamo, afirma que há muitos seres vivos dentro dela, muitos espíritos. Ele critica fortemente os brancos por serem tão destrutivos e apenas preocupados com as mercadorias.

Entre os Bororo, aprender a cantar pode acontecer a partir dos 40 anos. Pelo menos quando estive entre os Bororo, eles me diziam que este era um processo muito demorado. Um cantor Bororo é uma figura de destaque nos rituais e, sobretudo, nos longos ritos funerários que esse povo realiza.

Outras atividades também demandam longo tempo de aprendizado entre os povos indígenas. A caçada, a pesca, a coleta, conhecer a localização dos rios, as histórias das aldeias, o calendário, saber quais as plantas são úteis. $\mathrm{O}$ próprio aprendizado de uma mulher que se casa e deve aprender a cuidar de sua casa, de seus filhos, por vezes de sua sogra e sogro. Os Apinajé, segundo o casal Percília e Silivan Panhi ${ }^{4}$, iniciam o processo de educação com as palavras adequadas:

O pai e a mãe educam seus filhos de acordo com o que foi ensinado, os pais conversam com os filhos que tem que responder com as palavras adequadas. O homem fala $\boldsymbol{Y}, \boldsymbol{k a}, \boldsymbol{k w a k o ,} \boldsymbol{t}, \boldsymbol{t} \boldsymbol{k}, \boldsymbol{p a}$, e a mulher, $\boldsymbol{y}$, kema, $\boldsymbol{k a}$, xema. Se a criança responde com falta de respeito, ele pode pegar a criança e dar uma palmada para [aprender] a respeitar os mais velhos. Depois da palmada a mãe chama a criança e começa a caçar piolho.

No entanto, no dia de hoje as crianças não estão mais respeitando como antes;

4 Percília e Silivan Panhi colaboraram com esse texto explicando como o seu povo educa suas crianças. Eles enviaram suas observações via whatsApp, no dia 22 de maio de 2018. 
só [querem] assistir TV, jogar bola, celular no ouvido o tempo todo. Com isso, os pais jovens não estão sabendo educar seus filhos como antes...

\section{Percília e Silivan Panhi explicam que}

Na etnia Apinajé há vários rituais que são repassados aos jovens e isso também são ensinamentos, porque vai ter que repassar às nossas crianças e jovens. Por exemplo, quando uma criança vai passeando na aldeia e o marimbondo pica a criança e a madrinha vê aquilo, ela vai até a casa dos pais da criança e fala o que aconteceu com o menino. $\mathrm{O}$ pai fala e a madrinha fala que vão fazer um ritual do marimbondo e marcam o dia para realizarem o ritual do marimbondo. Quando chegar o dia, os pais da criança e os padrinhos e a comunidade vão até a casa do padrinho da criança realizar a cerimônia, e o avô e a avó vão também, para levar até a criança. E os avós vão pegar o marimbondo que começa a picar os avós e assim termina a cerimonia do ritual do marimbondo.

Importante observar que os rituais também são considerados formas de educação e de passagem de ensinamentos. Perdemo-nos no nevoeiro da ideia de que a educação indígena é informal e ela passa desapercebida e sempre a colocamos em oposição à escolar. Alguns trabalhos que eu consultei limitam-se a afirmar que a educação ocorre pela observação de adultos e nas brincadeiras. Nada muito mais que isso. Somos ignorantes a respeito. Assim como somos ignorantes de muitas das coisas dos povos indígenas. Gersem Baniwa, durante a conferência mencionada acima, ressaltou que "as cosmologias, ontologias e epistemologias ameríndias são muito pouco conhecidas no mundo acadêmico".

Recentemente houve um avanço nessa compreensão, depois que o antropólogo Viveiros de Castro formulou uma teoria sobre o que chamou de cosmologias ameríndias. As cosmologias ameríndias se opõem radicalmente à cosmologia não indígena, capitalista. Nesta, os seres humanos são separados radicalmente do restante da natureza, dos animais, dos rios. Todos os elementos da natureza estão sob o domínio da espécie humana e podem ser usados, estão à nossa disposição, doados pelo Deus do mundo cristão. Não há um planejamento de como usar os recursos naturais e nem uma 
preocupação com o futuro da humanidade. O que vigora nessa apropriação é uma ganância sem fim. Por este motivo, Kopenawa, em seu livro, demonstra muita preocupação com o futuro, pois na sua cosmologia, as árvores sustentam o céu e o não indígenas estão acabando com as florestas. Se elas acabarem, o céu cairá e tudo se acaba.

Se para os índios não há oposição entre homens e natureza, o que são os animais? São humanos, segundo Viveiros de Castro, em pele de animais. Para os Yanomamo (Kopenawa, 2015), os animais são ancestrais que vestiram a pele e assumiram o corpo de animais, em um ato de sacrifício para alimentar seus descendentes.

Outros autores, tais como Philipe Descola (1986), que estudou os Achuar, também fazem a mesma afirmação; a maneira dos povos indígenas estarem no mundo, e de se comportarem no mundo é completamente diferente da do mundo capitalista, que os quer englobar.

E outra cosmologia, muito outra. É outra ontologia, outra maneira de ser, muito outra. Neste sentido, a escola do mundo colonial imposta aos indígenas, aos povos africanos, somente pode ser uma das facetas da violência desse mundo.

Michel Taussig (1987) reflete sobre o terror na dominação colonial que teve papel decisivo na tentativa de extermínio dessas outras ontologias, dessas outras formas de ser. Kopenawa também se refere à chegada do homem branco em suas terras. A violência imediatamente se expressou por darem um nome a ele quando, ele explica, o nome para o povo dele é uma coisa séria, não se pronuncia, não se fala.

Sabedores que somos agora (mesmo que superficialmente) dessas outras ontologias, dessas outras cosmologias e epistemologias, poderemos refletir com mais propriedade sobre as relações entre índios e não índios e imaginar a profundidade da violência do contato.

O que estou interessada, de agora para a frente, nesta reflexão, é sobre especificamente os saberes, indígenas e não indígenas. Auxilia-me, nesse momento, Boaventura dos Santos, o autor português muito crítico do sistema capitalista e da colonialidade.

Ele propõe o conceito de epistemologias (no plural) do sul, para opor ao que chama de epistemologia do norte. Esse sul não é geográfico, mas se refere a tudo o que está fora do norte colonizador e opressor. O norte é a Inglaterra, a França, a Espanha, Portugal, 
enfim, os países que dominaram as Américas e África, sobretudo, impondo suas leis e sua ciência. A epistemologia do norte provocou um epistemicídio, ao lado dos canhões, das armas, das doenças levadas para a população dominada. Arrasou as populações da África e os povos indígenas das Américas, incluindo os da América do Norte, onde hoje estão os Estados Unidos.

Por sul, Boaventura entende um conjunto de saberes dos grupos sociais que sofrem injustiça, do capitalismo, do colonialismo e do patriarcado. A maior parte dos povos está no sul geográfico, mas há também no norte.

O que é que existe no Sul que escapa à dicotomia Norte/Sul, pergunta Boaventura.

Segundo esse autor, a ciência moderna é interessante, mas imaginar que é a única forma de conhecimento rigoroso e eliminar qualquer outro conhecimento, é absurdo. E essa política do conhecimento, que é muito agressiva, que aprofunda a dominação e o colonialismo. Essa política arrasa, destrói ou já destruiu muitos dos conhecimentos nas zonas coloniais. Ao lado do genocídio de povos dominados, ocorreu o epistemicídio, afirma Boaventura dos Santos. O colonialismo permitiu que os povos do "sul" tivessem passado, mas, o futuro era do colonizador. Por isso, se aprende na escola um índio no passado: "os índios eram, os índios moravam, os índios adoravam...".

Alguém pode argumentar que o colonialismo acabou. Gersem Baniwa (conferência) argumenta que o colonialismo deixou uma herança que opera em nossas mentes. A isso se chama de colonialidade. Ela hoje se apresenta como violento racismo, ou nas teorias evolucionistas que hierarquizam, que afirmam serem os índios e os negros inferiores e incapazes - de aprender, de estudar, de trabalhar, de serem ricos.

A colonialidade é marcada pela prática capitalista, e junto com ela a epistemologia do norte, a ciência dos "brancos" continua prevalecendo e provocando as ausências de outras formas de conhecimento.

Boaventura tem uma postura muito interessante. Ele recomenda que a ciência ocidental não deve ser descartada, mas a escola ideal deve dar espaço e visibilizar outras epistemologias. É muito estranho chegar em uma escola indígena, em uma aldeia, em plena terra indígena e deparar-se com cartazes em português, trazendo mensagens contidas nos livros didáticos escritos muito 
longe, tanto do espaço como da cultura do povo que frequenta aquela escola.

Há um abismo entre o conhecimento que se propaga para as crianças indígenas e o conhecimento produzido por seu povo. $O$ ideal seria que crescentemente houvesse produção de material didático pelos sábios e professores indígenas; não estou, como Boaventura, advogando que o conhecimento dos "brancos" seja totalmente negado. Imagino que uma boa escola permita que o aluno indígena acesse a ciência do norte, mas que esse venha acompanhado com uma boa dose de qualidade dos conhecimentos indígenas, produzidos por eles próprios.

Segundo Walter Mignolo, a interculturalidade não se refere a relações entre culturas distintas, mas implica trocas simétricas das epistemologias, em que as ausências dos sistemas de conhecimento e de saberes, sejam eliminadas. Essa proposta converge com o que Boaventura (2002) chama sociologia das ausências. Temos uma dívida em relação ao apagamento histórico do saber indígena pela violência colonial, violência que se perpetua na maior parte das escolas que funcionam nas aldeias, onde os livros, currículos, conteúdos, metodologia, calendário, obedecem fielmente às epistemologias do norte ${ }^{5}$.

Os cursos de formação de professores indígenas nas universidades federais de Minas Gerais, Roraima, Goiás e o da Universidade Estadual de Mato Grosso (UNEMAT), representam um avanço, uma vez que são voltados apenas para alunos indígenas buscando uma preparação para a atividade docente nas aldeias ${ }^{6}$.

Boaventura dos Santos (palestra) recomenda que a universidade deve romper com a ignorância e conhecer a profusão de conhecimentos que há no mundo. Esses cursos de formação permitem que a universidade receba contribuições e que se enriqueça com a

5 Nossos alunos do curso de formação de professores indígenas na UFG, invariavelmente relatam pressões por partedas Secretarias Estaduais deEducaçãoparaquesigamfielmentetodos oscânones dasescolasnãoindígenas.

6 Na Universidade Federal de Goiás, o sistema de cotas para pos-graduação foi iniciada no ano de 2017. O programa de Pós-graduação em antropologia recebeu uma aluna Krahô e um aluno Apinajé. Em 2018, uma grande demanda por parte dos candidatos indígenas resultou na aprovação de um aluno Akwẽ-Xerente no doutorado e de quatro no mestrado, sendo dois Xerente, um Tapirapé e um Xavante. 
presença dos alunos indígenas. De pouco adianta que se busque o conhecimento indígena através dos parâmetros do que chamamos de ciência, e tampouco que se transponha essa ciência para as formas de conhecimento indígena. Com esse formato de ensino, apenas se reproduz o poder colonial e se força que os paradigmas do conhecimento indígena sejam formatados nos moldes da nossa ciência ocidental.

É preciso que se compreenda que as epistemologias indígenas organizam o mundo e o conhecimento das coisas e seres nele contidos de uma maneira muito distinta com que operamos.

\section{Os projetos extraescolares e o estágio escolar: formas de enfrentamento de um processo colonial e silenciador das epistemologias indígenas}

Nesta parte, pretendo abordar a maneira que o curso da UFG trata essa ausência e o silenciamento das epistemologias indígenas, buscando reverter o quadro do epistemicídio.

O primeiro ponto é que o curso de formação de professores indígenas da UFG, a licenciatura intercultural, não é disciplinar, mas busca a transdisciplinaridade através do que se convencionou chamar de "temas contextuais". As aulas são ministradas através de temas, como por exemplo, "terra e territorialidade", "cultura e trabalho", "corpo e saúde", "cosmos e saberes", "percepção cultural do ambiente" etc. Estes temas permitem abordagens ampliadas que levem em consideração aspectos diversos de um mesmo problema; como os alunos indígenas são formados em uma matriz de conhecimento holística, para eles é muito fácil operar de uma forma transdisciplinar e as aulas sempre recebem contribuições do campo de conhecimento que cada etnia traz.

O segundo ponto é a forma como os estágios e os trabalhos de final de curso, chamados de "projetos extraescolares" são realizados. Ambos são negociados com a comunidade e trata-se ainda de um diálogo entre epistemologias do norte e sul. Os alunos dialogam intensamente com os paradigmas de nossos conhecimentos, com o conhecimento que eles trouxeram e os que descobriram através do exercício da pesquisa, entrevistando pessoas das aldeias, autoridades, anciões etc. A ponte epistemológica é responsabilidade 
deles. O principal aspecto dos trabalhos do estágio e dos projetos extraescolares é a pesquisa que devem realizar com seus familiares e conhecidos; neste momento, os mais velhos são os grandes responsáveis pela passagem das informações.

O estágio e os projetos extraescolares são uma busca de deixar o silêncio, as ausências de um sistema de conhecimento e trazê-lo para a ignorante universidade que acredita, que crê que a epistemologia do norte é a única referência segura e certa, e verdadeira, do conhecimento.

No caso dos alunos do povo Akwẽ Xerente, a quem acompanhei por nove anos, os alunos, ao fazerem seu estágio, buscam informações com seus wawe, as pessoas mais velhas e sábias. Esse exercício de, mais do que reforçar, ter segurança com o sistema de conhecimento está em andamento e todas as 26 etnias que frequentam o curso da Licenciatura Intercultural o fazem. Mas isso nem sempre é tão simples e tão fácil, pois nós, os professores da UFG, apesar de nossa posição crítica, ainda estamos presos ao modelo da epistemologia do norte e o aprendizado para nós exige um exercício de abertura e de rompimento com o campo disciplinar em que fomos formados.

Como superar essas barreiras? Gersem Baniwa, em sua conferência, observou que a cultura colonial está internalizada dentro de nós, indígenas ou não. Para destruir a "barraca" da colonialidade, é preciso construir outros modos de vida, que passam necessariamente pelo reconhecimento e pela valorização de outros conhecimentos.

As pedagogias indígenas, afirma Baniwa, têm muito que nos ensinar. As distintas culturas indígenas são formas de vida que quebram a hegemonia absoluta do mundo capitalista. Os índios resistem há mais de 500 anos, lembra ele, e não há sinal de que vão abrir mão de seus modos de vida.

Como apontou Kopenawa, no mundo capitalista, o povo das mercadorias não entende a vida da floresta e está acabando com ela, e ao acabar com ela, o céu vai cair. Os "brancos" não sabem nada dessas coisas. Contentam-se em pensar que somos mais ignorantes do que eles, apenas porque sabem fabricar máquinas, papel e gravadores.

Pensar descolonialmente e praticar a desobediência epistêmica são elementos fundamentais para romper com a razão imperial e afastar decisivamente a colonialidade. Desta maneira, é possível atingir a abertura para a enorme variedade de conhecimentos para 
além da epistemologia do norte. Os novos autores indígenas, tais como Gersem Baniwa, David Kopenawa e os alunos pesquisadores da licenciatura intercultural da UFG, crescentemente, concretizam essa realidade que há alguns anos atrás era quase inviável.

Para terminar, lembro com Pimentel da Silva (2011), que a experiência de produzir conhecimento é fundamental para o descolamento da colonialidade do sabere das políticas assimilacionistas. De acordo com ela, "produzir conhecimento não aponta apenas para o processo reconstrutivo técnico, mas principalmente para a habilidade de cada qual se tornar a fonte maior de suas oportunidades, na condição de sujeito que toma o destino em suas mãos" (Pimentel da Silva, 2011, p.06).

\section{Referências bibliográficas}

BANIWA, Gersem. Conferência proferida "A Gramática das Teorias Interculturais e o Império das Epistemologias Coloniais na Formação Superior”. III Congresso Internacional Formacion en Educacion Intercultural y Praticas de Descolonizacion en America Latina, 26 de julho de 2017.

DESCOLA, Philipe. La Nature Domestique. Symbolisme et práxis dans l'ecologie des Achuar. Paris, Édicions de la Maison des Sciences d'Homme, 1986.

KOPENAWA, David; ALBERT, Bruce. A queda do céu. Palavras de um xamã Yanomami. Editora Companhia das Letras, S.P., 2015.

LANDER, Edgardo (org). A colonialidade do saber: eurocentrismo e ciências sociais. Perspectivas latinoamericanas. Colección Sur Sur, CLACSO, Ciudad Autónoma de Buenos Aires, Argentina, 2005.

MIGNOLO, Walter. Cadernos de Letras da UFF - Dossiê: Literatura, língua e identidade, nº 34, p. 287-324, 2008. Desobediência Epistêmica: a opção descolonial e o significado de identidade em política.

PIMENTEL DA SILVA, M. do Socorro. Políticas linguísticas no estágio e nos projetos extraescolares, manuscrito, 2011.

SANTOS, Boaventura de Sousa. Para uma sociologia das ausências e uma sociologia das emergências, Revista Crítica de Ciências Sociais, 63, Outubro 2002: 237-280. Disponível em: <http://www.boaventuradesousasantos.pt/media/pdfs/Sociologia_das_ausencias_RCCS

63.PDF>. Acesso em: 30 maio 2018. 
SANTOS, Boaventura de Sousa. As epistemologias do sul e a descolonização da universidade. Conferência do Ciclo UFMG, 90, 2017. Desafios Contemporâneos. Disponível em: $<$ https://www.youtube.com/ watch? $\mathrm{v}=$ WoBJb8fzAdg $>$.

SILVA, Joana A. Fernandes. Rito das defesas de projeto extraescolar na terra dos Akwẽ: possibilidades de rompimento com a subalternidade e com a escola colonizadora. In: BORGES, Mônica Veloso; PIMENTEL DA SILVA, Maria do Socorro (org.). Educação Intercultural: experiências e desafios políticos pedagógicos. $1^{\mathrm{a}}$ ed. Goiânia: Editora da UFG, 2014, v. 1, p. 93-112.

SILVA, Joana A. Fernandes. Bororo Vive, encarte do disco com o mesmo nome, 1987.

TAUSSIG, Michel. Xamanismo, Colonialismo e o Homem Selvagem. Um estudo sobre o Terror e a Cura. Editora Paz e Terra, 1987.

XERENTE, Ercivaldo Damsokekwa. Processo de educação Akwẽ e os direitos indígenas a uma educação diferenciada: práticas educativas tradicionais e suas relações com a prática escolar Xerente. Dissertação defendida no Programa de Pós-graduação em Direitos Humanos, UFG, 2016.

Recebido para publicação em março de 2018.

Aceito para publicação em maio de 2018. 